\title{
Language Power in Attorney's Leading Questions to Discredit Witness's Testimonies during Court Trial: A Forensic Linguistic Study
}

\author{
Reski Ramadhani, Lia Maulia Indrayani, Sutiono Mahdi
}

Department of Linguistics, Faculty of Cultural Sciences, Universitas Padjadjaran, Indonesia

\begin{abstract}
The present research is intended to identify how leading questions adopted by attorney who challenges the testimonies provided by the witness during a court trial in a courtroom, namely cross-examination. Furthermore, through these questions, the kinds of linguistic features to build the language power of attorney during examination are also investigated. This issue is essential to be raised since courtroom examination is the most accomplished way to elicit all the significant and required information to provide a clear portrait of a case. It provides the judge a deep knowledge in deciding the final judgment. This research issues one of the phenomenal cases in Michigan regarding the crash between truck driver and police who was died at the moment in 2015. A qualitative descriptive is employed to analyze the data. The result revealed that most of the questions provided by the attorney during a court trial are leading questions through declarative question form. This indicates that the attorney attempts to provide the state of facts with the aim to confirm the information based on his point of view instead of eliciting wider information from the witness's side. Moreover, the most types of linguistic features that build the attorney's language power containing in the questions are 'so' summary, reformulation, vocabulary landscaping, and evaluative third turn which indicate that he attempts to control the topic of discussion and control witness's perception toward the issue which leads to the inconsistency ideas. This result can provide a damaging position of the witness since his testimonies can be considered as vulnerable information.
\end{abstract}

Keywords - language power, leading questions, attorney, witness, court trial.

\section{INTRODUCTION}

Courtroom serves a wealthy and interesting field of linguistic investigation. It explores an exclusive space of social engagement and a unique domain of language use. The decision created during the process is occasionally influenced by the interaction between the parties, for instance, between judge and witness, attorney or lawyer and witness, etc. (Oluwatobi, 2016). Furthermore, courtroom interaction consists of a more complex system through the means of asking a question and responding it because the asymmetrical relations among the parties affect the process in eliciting the pieces of evidence (Catoto, 2017). In this case, according to Gibbons \& Turell (2008), witnesses are powerless participants because they are only allowed to respond to questions provided by either jury or attorneys.

The use of language in the courtroom may determine the power that shows the asymmetry relationship between the companions. This is based on that, linguistically, language can be used to control other individuals' perceptions toward something (Supardi, 2016). Furthermore, it is also considered as the media that can be used to create and perpetuate the inequality distribution of power (Fairclough, 2003). The power which is owned by the jury or other investigators during the court process is expected to regularly avoid an unfair decision for the society who involved in particular cases. However, the result of the court decided by the jury occasionally may contradict to what is expected. It was happening in one of the cases in Michigan, United State where a suspect who was driving a car and killed and struck a Michigan State Police trooper in 2015 was found not guilty. The victim was getting death after his body found near the trailer parked. After investigating, the suspect's lawyer claimed that it was an accident that had not been intentionally caused and then the jury agreed (Bartkowiak, 2017). This case shows that an accused person was decided to be innocent, besides the regulation is implemented, it may be influenced by the interaction, such as examination between attorney or lawyer and witness, conducted during a court trial.

The present study has an objective to examine how the questions, mainly leading questions, are constructed by the attorney in testifying the witness's responses or testimonies during cross-examination and to investigate the linguistic features containing in the questions which build 
the power of the attorney. Temporarily, the investigation of language used in legal discourse has become one of the main concerns in the courtroom. However, the researches regarding language used during cross-examination are still rarely conducted. Cross-examination, the process where the attorney obtains an opportunity to examine the witness, is considered as the essential stage that must be conducted to elicit the required information which influences the result of the case. In fact, through this process, the attorney as the opponent attempts to seek and identify the inconsistency statements provided by the witness in order to get an opportunity to discredit or attack him/her testimony which may influence or create the doubtful observation in the mind of the judge ( $\mathrm{Ng}, 2010)$. Moreover, they even possess a strategy to provide discursive questions that function to coercive or to provide pressure to the witnesses in asserting what they do not actually aim to say and the result of the evidence may be twisted and altered for social injustice (Gibbons \& Turell, 2008).

Conducting an investigation on how questions are constructed during a court trial is crucially important. Questions can be rightly used to elicit significant information, on the other hand, it can be also utilized as a weapon to attack someone's credibility by providing such coercive ways. A leading question can be categorized as coercive questions because the intention of this question is to confirm the state of affair of the event based on the speaker's point of view instead of obtaining the essential and required information based on the addressee's versions (Griffiths \& Milne, 2006). This question should be avoided by attorneys, especially during the cross-examination process, in order to maintain the credibility and confidence of the witness so that the witness will not be positioned as a compromised side. In addition, Catoto (2017) mentions that attorneys are not allowed to provide questions that explicitly contain a coercive form in order to avoid the vagueness of the information which occurs in the case. This shows that the attorneys are demanded to provide the questions which lead to probe deeper information so that the clearness of the information can be obtained.

In relation to the present study, scholars who have devoted their concern to the language of the legal setting are highlighted. In term of how language is used in courtroom mainly cross-examination process, some recent studies conducted by several scholars have investigated various issue such as Balcha (2015) who examined the questioning patterns in legal discourse and the study revealed that the use of the declarative question, tag question, and projection question forms are the lawyer's discursive strategies to control and dominate the language of the witnesses. Moreover, some other researchers are Supardi (2016) who found that language power in the courtroom can be reflected in some persuasive features that influence the mind of the jury and Cerović (2016) also found that rhetorical questions are treated as a challenge on the testimonies of the suspect by the detectives. However, the present study highlights several dissimilar points from the previous study. First, the present study is conducted to find how the specific questions, mainly leading questions, are used to examine the witness testimonies. Then, this study particularly concerns with one of essential stage in courtroom which is crossexamination. Third, this study investigates different instrument of linguistic power containing in the leading questions to show how the attorney controls the information of the case. Last, this study selects different case that only focuses on the utterances of the attorney. Therefore, this study is expected to provide new insight on how questions provided by attorney involving the language power can control the perspective of the witness which influences the clearness of the information or the facts of the case.

\section{THEORETICAL FRAMEWORK}

\subsection{Overview of Courtroom Practice}

The process of courtroom depends on the interaction which is language is used to present the competing claim through a set of question and answer exchanges between judge, lawyer, and witness in which evidence or facts of a case are created. Luchjenbroers (1997) claims that the exchanges of questions and answers during court trials are intended to serve a case narrative construction in order to seek which decisions are appropriate to determine the guilty of the case. Furthermore, question and answer during the court trial are expected to elicit or obtain more information toward the case to create the justice decision in the final investigation. Furthermore, during communication, judges or counsels frequently impulse the witness to speak up so that they can carefully listen to their testimony. However, a witness is a powerless side since he is only allowed to answer the question (Gibbons \& Turell, 2008).

In courtroom practice, the stages or processes or known as a genre are differently constructed. Heffer (2005) and Gibbons (2003) differentiate courtroom genres into three types; those are procedural, adversarial, and adjudicative genres. Procedural genres refer to a ritualistic discourse orientation highlighting the essentials of formalized tradition. Then, adversarial genres are considered as a strategic discourse orientation as their ability to affect the outcome of a trial. On the other hand, adjudicative genres 
are a deliberative discourse orientation as they focus on the legal framing of the closing stages (Gibbons, 2003; Heffer, 2005).

Cross-examination is a legal process that appears in the court trial. It is the part of the adversarial legal system which consists of an oral presentation of evidence. $\mathrm{Ng}$ (2010) states that the purpose of cross-examination is to examine the witness which is done by the counsel or attorney in order to elicit or confirm the fact of the case. However, in this step, an attorney has another purpose in order to discredit the testimony provided by a witness in order to identify the inconsistencies which leads to a reasonable doubt in the perception of the jury or the judge. Moreover, according to O'Barr (2014), during crossexamination, the witness is tied into some rules where a witness is only allowed to respond to the question provided by the counsel and witness is generally prohibited to observe the question asked or to comment the process. These rules create the power of attorney in controlling the process where the intimidating process may not be avoided. The broader image of the courtroom genres can be seen in the following figures below:

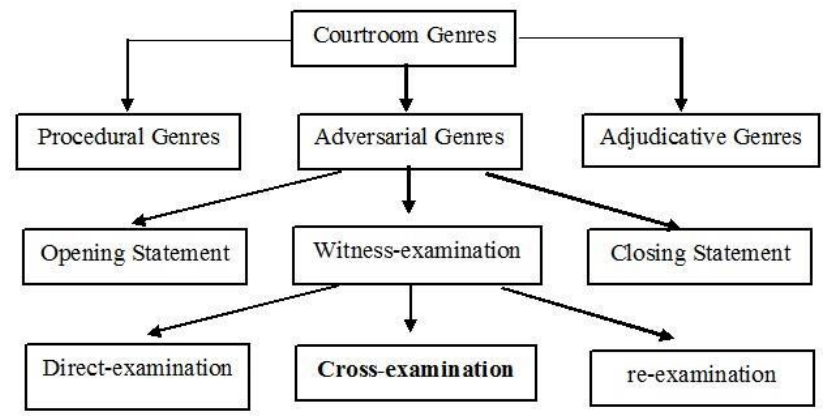

Fig.1: Courtroom Genres

\subsection{Leading Questions}

Leading question is the mode used to provide or suggest the hearer an answer or a response toward the question which is asked. This indicates that the hearer is led by the interviewer in which information should be given during interaction. Oxburgh, Myklebust, \& Grant (2010) argues that the aim of this type of question has a function to produce a response desired by an interviewer. In the courtroom context, leading questions or suggestive interrogations were considered to be a poor way of questioning especially during the cross-examination of opposing lawyers (Catoto, 2017). This is due to the objective of the examination to obtain clearer and broader information from the witness and this type of question can narrow or limit the certain information required. Furthermore, the rule of the court does not allow anyone to employ this type of question to those who are testifying in the courtroom whether they are the victim/complainant, suspect/accused, and witness. Moreover, this type of question can be actualized through declarative question and tag questions where the speaker asserts something which contains a suggestion to lead the hearer's opinion. According to Gibbons \& Turell (2008), declarative question and tag question form are one unusual way of asking a 'question' in court in such a way that it contains the lawyer's version, and puts pressure on the witness to agree, is to put the question as a blunt statement rather than in interrogative form and await the witness's agreement.

\subsection{Language Power}

As stated earlier, language contains a power that can be used based on particular purposes such as persuasive function, communicative function, and etc. In forensic linguistics, in investigating power, it can be separated into two kinds of power which are the power of language and the power of law. According to Cheng (2016, p. 5), "the power of law is much more visible and overt, seen and experienced every day by many and all of us, on the other hand, the power of language or linguistic power is much more subtle and invisible, and most people are unaware of it even though most use that power every day and exert its power to achieve one's ends in different circumstances and contexts for better or worse". However, the present study focuses on the power of language or linguistic power used by an attorney or lawyer in the courtroom.

Language or linguistic power frequently occurs in an implied and invisible way since language is so natural and genuine to all of us and also it generally spreads its power and affects us without realizing it. Gibbons (2003) states that language has the power to inform and enlighten as well as misinform and mislead. In addition, Habermas (2014) also argues that the primary function of language is not only to provide the understanding and clearness but also it shows the potential instrument of power and inequality in the public circle, especially in institutional contexts. Gibbons (2003), Tkačuková (2011), and Thornborrow (2014) provide some instruments in order to investigate the linguistic power used by individuals such as counsels or lawyers in an interaction, especially in the courtroom discourse, which are explored below.

\subsection{1 "So" Summary}

'So' summary is as one of the linguistic features which are used by an individual to control the intention of topic discussion during an interaction that they are always prefaced by the particle 'so'. According to Gibbons (2003), the use of 'so' summary is intended to play an evaluative role and in a way that expects and assumes agreement from the addressee. This means that individual tries to summarize the points which have previously mentioned in order to clearer the arguments or to confirm 
what has been agreed by the interlocutors. In addition, in courtroom interaction, 'so' summary is used by the counsel or attorney as the linguistic power which prefaces the questions with the particle 'so' to create the proposition in the question sound like the only logical one in the state of affairs (Gibbons, 2003). Moreover, Johnson (2002) argues that 'so' summary can be utilized to recapitulate a witness's statements in which the witness is assumed to concur with the examiner's point of view.

\subsubsection{Reformulation}

Reformulation is the linguistic feature that contains power for the individual by the way of reformulates previous proposition into different forms but it still has a similar purpose. Gibbons (2003) states that reformulation is one strategy to examine the witness' previous statements as incomplete or inaccurate and purpose to obtain more discrediting responses. It can be also assumed that reformulation form is the way to state a similar purpose but to use different structures or words (synonym). Reformulation is also intended to manage the topic during examination in order to compliance the witness to keep on the topic asked by the lawyer.

\subsubsection{Vocabulary Landscaping}

A word or vocabulary choice is considered a powerful tool employed by an individual to control the interaction. This reason is clearly agreed because the perception either positive or negative received by the public toward something is based on how words are chosen. In addition, words that are used can support the state of affairs or even threaten someone's ideas. Thornborrow (2014) and Danet (1980) argue that vocabulary choice can be a powerful tool used by counsel during examination where the words which contain certain connotations are taken corresponding to the reality of an examiner expects to represent. For instance, the words 'baby' and 'foetus', 'freedom fighter' and 'guerrilla' or 'terrorist' tend to have a similar reference, however, their implementation may mean to deliver either positive or negative evaluation of the particular things (Danet, 1980).

\subsubsection{Evaluative Third Turn}

The third turn is the effective tool which can be used by an individual to challenge answer, especially during an examination. The aim of the third turn is to give feedback to someone whether his or her responses were correct or not. Furthermore, in the courtroom context, the use of the third turn is also intended to refuse the veracity of the testimony provided by the witness. As Gibbons (2003) argues that the third turn is the structure placed at the end of elicitation-reply order which can be implemented to provide an evaluation of the witness's testimony either in an encouraging way such as correct, good, that's right or in a challenging way such as no, that's not what I asked you, or no, no, no. In addition, Luchjenbroers (1997) adds that the lawyer uses evaluative third turn as linguistic power to positively or negatively comment on the testimony provided by the witness to a question. This is inherent with the goal of the lawyer during crossexamination which mainly to discredit the witness's version toward the state of affairs.

\section{METHODS}

The current study employs a qualitative descriptive approach. Qualitative research is a great way to explore a research problem in case that the variables are unknown (Creswell, 2012). In addition, the qualitative method observes the actions and structures of the preferred variable (Tracy, 2019). In this case, linguistically, according to Litosseliti (2017), the qualitative method focuses on the patterns and structures of the linguistic variable. In this present study, qualitative research is used to explore how leading questions are implemented by the attorney during court trial and how the language power is distributed containing in the questions to discredit the testimonies provided by the witness. Therefore, there some steps conducted in this study that begins with observing the interaction between attorney and witness, conceptualizing the types of leading questions used by the attorney, analyzing the language power adopted by the attorney, and drawing a conclusion that defends the premises.

The data are taken from the transcription of the crossexamination video through Neil Rockind's official website in 2015. There are two lay-witnesses who are examined in this case by lawyers (Rockind, 2018). Furthermore, the data does not need to get permission from the institution because it can be publicly consumed and the court trial process is also lived on the television. Neil Rockind is one of Michigan's most recognized criminal defense trial lawyers and known as the "go-to" attorney for difficult, high profile criminal cases (www.top100criminaldefenseattorneys.com). This case is between defended Charles Warren and Police Trooper Chad Wolf who is dead after a motor vehicle accident in 2015. Warren was charged with reckless driving causing death and leaving the scene of an accident causing death. Warren was acquitted by a jury after a lengthy trial. Several eyewitnesses testified during the trial and the video is a cross-examination between Neil Rockind as the lawyer and the witnesses. This case is interesting because, in the last of the jury's decision, Charles Warren is decided to be innocent for the case. 
IV. RESULTS AND DISCUSSION

In this part, the result of the classified data is presented. After reducing data, it is showed that there are 96 data which refers to leading questions which is divided into declarative question and tag question forms. For further explanation and discussion, the samples of the data are provided below and the data are also presented by using the code in order to make the data analysis easier.

\subsection{Excerpt 1}

$1 \mathrm{Q}$ : You got onto I-75 at Dixie Hanuman, right?

2 A : Yes.

$3 \mathrm{Q}$ : And that feeds into the left-wing?

$4 \mathrm{~A}$ : Yes.

$5 \mathrm{Q} \quad$ : It's fastening?

$6 \mathrm{~A}:$ The fast lane, yes.

7 Q : So, it's a different type of entrance than we call normal, right?

8 A : Yes, you have to navigate that in the French' map.

From excerpt 1 above, it reveals that there are four questions that are referred to leading questions which are numbers $1,3,5$, and 7 . In the data number 1 , the attorney proposes a question regarding the specific place that the witness passed at the moment of the accident by mentioning "I-75 at Dixie Hanuman". This question refers to a leading question because the attorney provides a picture or suggestion to the witness in terms of how his perception toward the situation portrayed. Furthermore, the pictures of the situation are based on the attorney's point of view. Moreover, the leading question is realized with declarative question form since it does not involve either the information question $(5 \mathrm{~W}+1 \mathrm{H})$ or changing the position of verb to the preceding of the sentence, however, it is structurally formed as a question by adding the question mark (?) in the last of the sentence (Gibbons \& Turell, 2008). In other words, syntactically, the form of the question follows the declarative form starting with a subject, verb, and complement and (?) as the question mark. In addition, the intention of this question is to confirm or to clarify the information provided by the attorney instead of eliciting the broader information from the witness's point of view. In other words, the attorney attempts to propose his version and the witness can only agree or disagree with it. Similarly, leading questions through declarative forms also occur in the data number 3 where the attorney interrogate regarding the situation and the speed of the witness's vehicle while he was driving it. In these questions, the attorney provides a picture and leads the witness to the conclusion of the situation. Similar to the previous question, in the data 7 , he also adopts a declarative form question to ask about the entrance of the rest area and he suggests his version toward the situation which was happening in that time in order to lead the witness assumption in accordance with what is intended.

In terms of the language power containing in attorney's questions above, firstly, 'so' summary occurs in that questions, mainly in question number 7. Regarding the theory mentioned above, 'so' summary is used as the intention to control the topic discussed during the interview which is prefaced by the article 'so' in order to evaluate the statement and to get the agreement toward the point of view provided. In this case, the attorney wants to conclude that the entrance that the witness takes is different from what people should normally take and the witness agrees with it which makes the proposition provided by the attorney stronger and clearer. Then, the attorney also selects the word "normal" which can be assumed that the witness was doing something outside of what it should be usually done by others and it may lead or result in a harmful impact. Moreover, besides 'so' summary and how the vocabulary is selected, the attorney also uses the evaluative third turn mark in his questions. In this case, he uses the evaluative third turn mark 'right' which is intended to challenge the witness's testimonies, to emphasize his point of view, and to evaluate the information which is considered to be true. This language power occurs in questions number 1 and 7 where the attorney wants to emphasize whether the witness takes I75 at Dixie Hanuman and the unnormal entrance. Basically, this type of information has been provided in the previous investigation and the attorneys have known the answer. If the witness answered 'no' toward the questions, it might impact his testimonies.

\subsection{Excerpt 2}

$1 \mathrm{Q}$ : When you saw Mr. Warren and trailer pull into the rest area you had a thought to yourself in that point, correct?

$2 \mathrm{~A}:$ :Yes

3 Q : You had choices that you could made in that point, right?

$4 \mathrm{~A} \quad$ : Yes.

$5 \mathrm{Q}$ : For example, you could have decided that he wanted to redial 9-1-1 if you thought there was a need to do so, correct?

$6 \mathrm{~A}$ : Correct.

7 Q : Like, hey this guy, I'm sorry you drive out of the limit, it was not one of your minds, right?

$8 \mathrm{~A}$ : Right, that never went through mind.

$9 \mathrm{Q}$ : That never went through your mind, right?

$10 \mathrm{~A}$ : Yes. 
There are five questions provided by the attorney in this excerpt, which is questions number $1,3,5,7$, and 9 . In question number 1 , the attorney attempts to clarify regarding what comes to his thought when seeing $\mathrm{Mr}$. Warren and the trailer got into the rest area. This question refers to a leading question because the attorney provides a portray of the situation to the witness on how his point of view toward the state of affairs happened. Structurally, this leading question is categorized into declarative question form since it is formed with a statement that ends with question (?) mark. Similar to questions number 3, 5, 7, and 9 , those are also categorized as a leading question through declarative question form because those are structurally similar to question number 1 . Question number 3 has a relation with the questions number $1,5,7$, and 9. The attorney attempts to provide a description or a picture regarding the situation happening at the moment and how the decision that should be carried out is also provided in order to lead the witness's perception and he can only agree or disagree with it instead of providing more information or his version toward the state of affair. Furthermore, this is the way of the attorney to make the witness provide the particular information or answer based on what he desires and he can also control the topic discussion which avoids witness to provide unnecessary information.

In some of the questions above, those also contain some language powers. First, the reformulation of questions is used. It has been stated earlier that reformulation is the linguistic feature that contains power for the individual by the way of reformulates previous proposition into different forms but it still has a similar purpose. This occurs in question number 1 and 3 where the attorney provides an equal proposition in the questions regarding what things that appeared in witness's thought about the points mentioned previously. However, he reformulates the question into a different form of a question as if it has a different topic in order to emphasize the information and answer provided by the witness. Furthermore, the repetition also occurs in question number 9 where the attorney uses the answer of the witness into the question in order to also emphasize that the witness never thinks about that points mentioned by the attorney before. Then, some of the evaluative third turn marks are also occurred at the end of the questions, mainly the words 'correct' and 'right'. These marks are used to challenge the witness whether what the attorney proposes is truth or not. If the witness agrees with the proposition, it will become the truth, and vice versa.

\subsection{Excerpt 3}

$1 \mathrm{Q}$ : Okay, so normally when you turn onto or go on to the highway and I'll pull up a map here in a second. Let me go onto the highway here, you're merging into the slow thing of the right lane, yes?

2 A : Yes.

$3 \mathrm{Q}$ : So, you listen to your glass, yes?

$4 \mathrm{~A}$ : Yes.

The excerpt 3 above shows that there are two questions provided which are categorized as leading questions. In these questions, the attorney attempts to provide a series of pictures toward the state of affairs which followed by the questions, mainly declarative questions form. For question number 1 , the attorney firstly explains the direction or the way that witness should take when he was driving at the moment of the accident. He attempts to lead the witness's perception by providing the answer or suggested information based on his point of view. Furthermore, it is a declarative question form since it is structurally begun with subject, verb, complement, and question mark (?) at the end of the sentence. In this case, the witness can't provide wider information based on his version because, regarding the question provided by the attorney, he can only provide an answer with 'yes' or 'no' answer or he can only agree or disagree with it. Furthermore, similar to the previous question, question number 3 also refers to the leading question through the declarative question. Structurally, it follows the patterns of the declarative question, which is subject, verb, complement, and question mark (?) at the end of the sentence.

Regarding the language power containing in the questions, firstly, 'so' summary occurs. This language power occurs in question number 3 which is marked by the article 'so' at the beginning of the sentence. This indicates that the attorney attempts to evaluate and to conclude the facts provided in the preceding statement in order to strengthen the proposition or information toward the state of affairs. If the witness agrees with the ideas, it will indicate that it becomes a truth. Then, another language power occurring is evaluative third turn mark which is indicated by “yes'. By using this mark, the attorney attempts to emphasize that the witness is really joining into the slow lane and he is really listening to his glass. In addition, he also attempts to challenge the witness's perception by creating logical construction toward the state of affairs. In this position, the witness can only agree or disagree with it.

\subsection{Excerpt 4}

$1 \mathrm{Q}$ : And I know that you thought that it was about four miles or so to get the rest area, is that right?

2 A : Yes, three to four miles.

$3 \mathrm{Q}$ : You are understanding that Tommy invited 
you, if you know this is not that the rest area, it is actually exit 96 , isn't it?

4 A : I'm not sure exactly which one I had stopped, there are numerous times.

5 Q : But it's exits 96 and 93 between three miles, isn't it?

$6 \mathrm{~A}:$ : Yes, between three miles, it's that correct.

The data above indicates that there are three different questions provided by the attorney, which is questions number 1, 3, and 5. Those questions are categorized as leading questions since the attorney leads or provides suggestions in the questions where the witness is only necessary to answer 'yes' or 'no' which indicates whether he agrees or disagrees with the proposition constructed. In question number 1 , it is a leading question realized through the declarative form. Attorney gives suggestions for the answer where he assumes that the witness had thought that the distance between his position into the rest area is about three or four miles. He attempts to lead the witness into the specific information instead of asking based on the witness's opinion. Structurally, the first question contains assertation which formed as a question. On the other hand, question number 3 and 5 are categorized as leading question realized through tag question form. This is indicated by the tag mark at the of the question 'isn' $t$ it'. In these questions, the attorney attempts to provide his point of view which leads the witness assumption regarding what the exit that witness took at the moment of the accident. In this case, the attorney mentions 'exit 96'. Similar to question number 5 , the attorney also clarifies the same information by emphasizing the specific number of the exit which makes the witness agrees with it. This is one of the attorney's strategy during cross-examination in order to control topic discussion so that the information provided by the witness should be based on what is required to positively strengthen his client's position.

In terms of the language power containing in the attorney's question, reformulation of question is used. It is realized through question number 3 and 5. As mentioned above, the reformulation form is the way to state a similar purpose but to use different structures or words (synonym) (Gibbons, 2003). In question number 3, the attorney asks regarding the number of exits that the witness took. However, the witness is uncertainly sure about the specific numbers. Then, in question number 5 , the witness attempts to reformulate the question in different ways but it has the same intention and presupposition. This strategy is used in order to control the topic discussion and to get the obvious answer from the witness which has not been satisfactorily obtained. Moreover, the witness also implements the evaluative third turn through the words "is that right" in order to emphasize his point of view.

\section{CONCLUSION}

Based on the analysis of the data, it is found that most of the question provided by the attorney during a court trial in the courtroom is the leading question realized through declarative question and tag question forms. The declarative form contains a high proportion of the data. This indicates that, during the court trial, the attorney attempt to lead the witness perception and assumption toward the information of the case by providing some specific information based on his point of view or version instead of obtaining wider information from the witness. This also shows that the witness attempts to maintain topic discussion which can discredit the witness's testimonies in front of the jury since the witness cannot provide another specific information that he has already had. In addition, regarding the language power containing in the attorney's questions, it revealed that all of the features of language power, which are 'so' summary, reformulation of the question, vocabulary landscaping, and evaluative third turn, appear. By using these features, the attorney can implicitly control the information during the interview which can strengthen his position and his arguments provided during the court trial. Therefore, linguistically, this type of question should be avoided by the attorney during a court trial in order to get the obvious information, neglect the vagueness, and create justice in the courtroom which can provide a positive impact for society. The present study is expected to provide insight regarding how questions and language are constructed by the attorney during a court trial in a courtroom in order to realize the society to avoid the harmful effect after becoming either a lay-witness or expert witness in the courtroom process. Furthermore, it can also alert the attorney to be aware of his linguistic in order to avoid the harmful effect for the society, especially for whom that was involved in the courtroom process.

\section{REFERENCES}

[1] Balcha, E. B. (2015). Analysis of legal discourse in crossexamination questionings: adama city criminal courtrooms, oromia regional state, ethiopia. The Journal of Teaching for Specific and Academic Purposes, 3(2), 6.

[2] Bartkowiak, D. J. (2017). Michigan man found not guilty on all counts in state trooper's i-75 dragging death. Click on Detroit. Retrieved from https://www.clickondetroit.com/news/michigan-man-foundnot-guilty-on-all-counts-in-state-troopers-i-75-draggingdeath

[3] Catoto, J. S. (2017). On Courtroom Questioning: A Forensic Linguistic Analysis. 33. 
[4] Cerović, M. (2016). When suspects ask questions: Rhetorical questions as a challenging device. Journal of Pragmatics, 105, 18-38. https://doi.org/10.1016/j.pragma.2016.09.010

[5] Cheng, L. (2016). Exploring courtroom discourse: the language of power and control (1st ed.). https://doi.org/10.4324/9781315581620

[6] Creswell, J. W. (2012). Educational research. Pearson.

[7] Danet, B. (1980). Language in the Legal Process. Law \& Society Review.

[8] Fairclough, N. (2003). Analysing discourse: textual analysis for social research.

[9] Gibbons, J. (2003). Forensic linguistics: an introduction to language in the justice system. Wiley.

[10] Gibbons, J., \& Turell, M. T. (2008). Dimensions of Forensic Linguistics. USA: John Bejamins B.V.

[11] Griffiths, L., \& Milne, B. (2006). Will it end in tiers? Police interviews with suspects in Britain. Investigative Interviewing: Rights, Research, Regulation, 167-189.

[12] Habermas, J. (2014). On the Pragmatics of Communication. John Wiley \& Sons.

[13] Heffer, C. (2005). The language of jury trial: a corpusaided analysis of legal-lay discourse. Springer.

[14] Johnson, A. (2002). "So...?? pragmatic implications of soprefaced questions in formal police interviews." Basingstoke: Palgrave Macmillan.

[15] Litosseliti, L. (2017). Research methods in linguistics. Bloomsbury Publishing.

[16] Luchjenbroers, J. (1997). 'In your own words ...': Questions and answers in a supreme court trial. Journal of Pragmatics, 27(4), 477-503. https://doi.org/10.1016/S03782166(96)00033-1

[17] Ng, E. (2010). Garmentor upper garment? A matter of interpretation? In tomblin (eds.). Proceedings of the International Association of Forensic Linguists' Tenth Biennial Conference. Retrieved from https://www.researchgate.net/publication/328130843_THE_ ROLE_OF_FORENSIC_LINGUISTS_IN_COURTROOM_ CROSS-EXAMINATIONS

[18] O'Barr, W. M. (2014). Linguistic evidence: language, power, and strategy in the courtroom. Elsevier.

[19] Oluwatobi, S. O. (2016). The role of forensic linguists in courtroom cross-examinations. 12(2), 12.

[20] Oxburgh, G. E., Myklebust, T., \& Grant, T. (2010). The question of question types in police interviews: A review of the literature from a psychological and linguistic perspective. International Journal of Speech Language and the Law, 17(1). https://doi.org/10.1558/ijsll.v17i1.45

[21] Rockind, N. (2018). Cross examination | eyewitness 1 | charles warren chad wolf trial $\mid$ acquittal. Retrieved from https://www.youtube.com/watch?v=DI0m5ixvZUA\&t=111s

[22] Supardi. (2016). Language power in courtroom: the use of persuasive features in opening statement. Indonesian Journal of Applied Linguistics, 6(1), 70-78. https://doi.org/10.17509/ijal.v6i1.2663

[23] Thornborrow, J. (2014). Power Talk: Language and Interaction in Institutional Discourse. Routledge.
[24] Tkačuková, T. (2011). Lay people as cross-examiners: a linguistic analysis of the libel case mcdonald's corporation $\mathrm{v}$. helen steel and david morris. International Journal of Speech Language and the Law, 17(2). https://doi.org/10.1558/ijsll.v17i2.307

[25] Tracy, S. J. (2019). Qualitative research methods: collecting evidence, crafting analysis, communicating impact. John Wiley \& Sons. 